\title{
PENGARUH AKSESTABILITAS, KOMPETENSI, SIKAP MONETER, DAN PENGALAMAN POSITIF PENGGUNA JASA ASURANSI PRUDENTIAL DI YOGYAKARTA
}

\author{
Inti Dian Lisnawati \\ IBN Udayana
}

\author{
Fakultas Ekonomi \\ Universitas Sarjanawiyata Tamansiswa Yogyakarta \\ E-mail:intidianlisnawati@gmail.com
}

\begin{abstract}
This study was aimed to analyze the factors that influence prudential insurance purchasing decisions in Yogyakarta. The variables of this study were the acceptability of insurance conditions, competency of insurance services, monetary attitudes of consumers towards insurance, a positive experience of insurance user and insurance purchasing decisions. The population in this study was the Prudential consumers, which is located in Sleman, Kulonprogo, and Yogyakarta. The sampling technique was using Probability Sampling. The data was collected using a questionnaire. The analysis technique used was multiple linear regression with a significance level of $5 \%$. The results showed the multiple linier regression model is $\mathrm{Y}=-0,058 \mathrm{X} 1+0,280 \mathrm{X} 2+$ $0,295 \mathrm{X} 3+0,307 \mathrm{X} 4$. Acceptability of insurance conditions showed no significant effect on insurance purchasing decisions. Competency of insurance services showed positive effect on insurance purchasing decisions. Monetary attitude of consumers on insurance showed positive effect on insurance purchasing decisions. Positive insurance user experience showed positive effect on insurance purchasing decisions.
\end{abstract}

\section{Keywords: acceptability of Insurance conditions, competency of insurance services, monetary attitudes of consumers towards Insurance, a positive experience of insurance user, insurance purchasing decisions}

\section{PENDAHULUAN}

Asuransi merupakan salah satu bisnis yang memberikan jasa keuangan kepada para pelanggannya. Perusahaan asuransi merupakan lembaga keuangan yang non bank yang bergerak dalam bidang layanan jasa dalam mengatasi risiko yang terjadi di masa yang akan datang yang diberikan kepada masyarakat. Asuransi memberikan banyak manfaat bagi kehidupan manusia.Manfaat yang paling utama adalah memberikan ketenangan kepada anggotanya.Misalnya, saat terjadi kecelakaan, saat sedang di rawat di rumah sakit, maupun bagi pendidikan anak-anak. Seperti halnya kejadian kecelakaan pesawat yang terjadi pada tanggal 5 Oktober 2015 lalu, yaitu pesawat
Aviastar, dimana semua penumpang dan kru pesawat meninggal dunia. Pada kecelakaan tersebut, ahli waris masing-masing penumpang akan mendapat klaim sebesar Rp 50.000.000 dari jasa raharja (www.okezone.com). Tentunya dengan adanya klaim tersebut dapat meringankan beban anggota keluarga yang ditinggalkan.Dengan demikian banyak manfaat yang dapat diambil apabila mengikuti asuransi.

Perkembangan perusahaan asuransi di Indonesia semakin pesat, seiring semakin mudahnya pemberian ijin pendirian perusahaan asuransi oleh pemerintah. Menurut Asosiasi Asuransi Umum Indonesia (AAUI), hingga kuartal III-2013, premi bruto asuransi umum meningkat jika dibandingkan periode yang sama 
tahun sebelumnya, yaitu mencapai $18,7 \%$ atau sebesar $\mathrm{Rp} 33,9$ triliun. Kondisi ini menunjukkan bahwa kesadaran masyarakat akan pentingnya memiliki asuransi semakin meningkat. Namun, meningkatnya kesadaran masyarakat ini tidak diikuti dengan peningkatan layanan oleh perusahaan asuransi kepada masyarakat.Banyak kasus yang menunjukkan bahwa perusahaan asuransi belum mempunyai kinerja yang maksimal sehingga menimbulkan ketidakpuasan para nasabah.Seperti kasus yang menimpa Asuransi Jiwa Bumi Asih Jaya (BAJ Life).Perusahaan asuransi tersebut mengalami masalah keuangan, akibatnya banyak nasabah yang khawatir dengan polis mereka, sehingga memilih untuk mencairkan sebelum jatuh tempo.Perusahaan asuransi sanggup mengembalikan namun membutuhkan waktu yang lama, bahkan ada yang belum terbayarkan hingga saat ini.Kondisi membuat nasabah merasa tidak puas atas pelayanan asuransi.

Terdapat banyak faktor yang mempengaruhi konsumen dalam memilih dan memutuskan penggunaan suatu produk.Menurut Essael (1987) dalam Iriani dan Maria (2012), terdapat tiga faktor yang mempengaruhi pengambilan keputusan konsumen yaitu faktor individual konsumen yang meliputi pendidikan dan penghasilan konsumen, faktor lingkungan dan faktor strategi pemasaran. Pendapat lain menyebutkan bahwa faktor-faktor yang mempengaruhi perilaku pembelian konsumen adalah faktor budaya, sosial, pribadi dan psikologis (Kotler dan Armstrong, 2008).

Menurut Hsee and Kunreuther (2000) dalam Ulbinaite et al (2013) dalam hal asuransi, seringkali keputusan pembelian asuransi dan klaimnya hanya bergantung pada faktor kuantitas spesifik seperti premi, probabilitas kehilangan dan nilai kompensasi. Saat memutuskan untuk membeli jasa asuransi sebagai suatu transaksi moneter, konsumen cenderung membuat keputusan berdasarkan analisis cost-benefit. Keputusan seperti ini pada umumnya bertujuan untuk memperoleh return finansial yang cukup daripada tujuan proteksi secara keseluruhan.
Selain faktor-faktor di atas, keputusan pembelian asuransi juga ditentukan oleh faktor sosial, psikologis dan emosional (Kunreuther and Pauly, 2005 dalam Ulbinaite et al, 2013). Faktor sosial menunjukkan alasan seseorang membeli produk asuransi karena orang lain juga membeli produk asuransi. Faktor psikologis menunjukkan bahwa seseorang membeli produk asuransi karena faktor label atau nama. Misalnya konsumen akan setuju membeli jasa yang dilabeli dengan nama asuransi daripada proteksi, karena sebutan asuransi memberi kesan positif, sedangkan sebutan proteksi memberi kesan negatif. Faktor emosional menekankan keputusan pembelian asuransi lebih difokuskan pada barang berharga dibandingkan dengan barang sejenis namun tidak spesial.

PT. Prudential Life Assurance Indonesia merupakan bagian dari Prudential plc, sebuah grup perusahaan jasa keuangan yang terkemuka dari Inggris yang mengelola dana sebesar lebih dari USS 510 milliar dan melayai lebih dari 21 juta nasabah di seluruh dunia. Perusahaan ini juga yang pertama kali meluncurkan produk asuransi yang dikaitkan dengan investasi di Indonesia, yaitu pada tahun 1999. Prudential juga menawarkan berbagai produk yang sesuai dengan kebutuhan nasabah, seperti PRUlink fixed pay, PRUlife, PRUlife for juveniles, PRUmajor medical, PRUaccident plus, PRUprotector plan, PRUmed, PRUlink assurance account plus, PRUlink investor account dan PRUlink syariah assurance account.

Berdasarkan uraian di atas, maka peneliti tertarik untuk melakukan penelitian dengan judul "Pengaruh Akseptabilitas, Kompetensi, Sikap moneter, dan Pengalaman Positif Pengguna Jasa Asuransi Prudential di Yogyakarta". Berdasarkan latar belakang masalah yang telah diuraikan, maka penulis moncoba untuk merumuskan masalah dalam penelitian ini adalah:

a. Apakah akseptabilitas asuransi berpengaruh terhadap keputusan pembelian asuransi? 
b. Apakah kompetensi penyedia jasa asuransi berpengaruh terhadap keputusan pembelian asuransi?

c. Apakah sikap moneter konsumen berpengaruh terhadap keputusan pembelian asuransi?

d. Apakah pengalaman positif berpengaruh terhadap keputusan pembelian asuransi?

\section{METODOLOGI PENELITIAN}

Penelitian ini bersifat korelasional yaitu suatu penelitian yang bertujuan untuk mengetahui hubungan antara beberapa variabel indepeden atau bebas terhadap variabel dependen atau terikat.

\section{HASIL DAN PEMBAHASAN}

Dari hasil analisis regresi linier berganda diperoleh hasil tentang koefisien regresi, dan $\mathrm{p}$ -
Variabel dependen dalam penelitian ini adalah akseptabilitas kondisi asuransi, kompetensi penyedia jasa asuransi, sikap moneter konsumen terhadap asuransi, dan pengalaman positif konsumen berasuransi, sedangkan variabel independen dalam penelitian ini adalah keputusan pembelian asuransi.

Sumber data penelitian ini berasal dari data primer. Data primer yaitu data yang berasal langsung dari sumbernya dalam hal ini berasal dari responden. Pengumpulan data primer dalam penelitian ini menggunakan metode kuesioner

Dalam penelitian ini teknik analisis data yang digunakan adalah regresi linier berganda. value. Hasil analisis regresi linier dapat ditunjukkan seperti pada tabel dibawah ini :

\section{Coefficients $^{\mathrm{a}}$}

\begin{tabular}{|c|c|c|c|c|c|c|}
\hline & & \multicolumn{2}{|c|}{$\begin{array}{l}\text { Unstandardized } \\
\text { Coefficients }\end{array}$} & $\begin{array}{l}\text { Standardized } \\
\text { Coefficients }\end{array}$ & \multirow[b]{2}{*}{$\mathrm{t}$} & \multirow[b]{2}{*}{ Sig. } \\
\hline \multicolumn{2}{|c|}{ Model } & $\mathrm{B}$ & Std. Error & Beta & & \\
\hline \multirow[t]{5}{*}{1} & (Constant) & 8.271 & 10.811 & & .765 & .448 \\
\hline & akseptabilitas & -.054 & .116 & -.058 & -.465 & .644 \\
\hline & kompetensi & .223 & .099 & .280 & 2.253 & .028 \\
\hline & sikap moneter & .300 & .124 & .295 & 2.425 & .019 \\
\hline & $\begin{array}{l}\text { pengalaman } \\
\text { positif }\end{array}$ & .388 & .155 & .307 & 2.499 & .015 \\
\hline
\end{tabular}

a. Dependent Variable: keputusan penggunaan

Hipotesis pertama yang menyatakan bahwa akseptabilitas kondisi asuransi berpengaruh positif terhadap keputusan pembelian asuransi, tidak terbukti. Ditunjukkan oleh nilai koefisien regresi sebesar $-0,054$ dan nilai probabilitas sebesar $0,644>0,05$. Hal ini berarti akseptabilitas kondisi asuransi bukan merupakan faktor utama yang mempengaruhi keputusan pembelian asuransi. Tidak signifikannya pengaruh akseptabilitas kondisi asuransi terhadap keputusan pembelian asuransi mengindikasikan bahwa keputusan pembelian asuransi Prudential oleh konsumen bukan disebabkan karena faktor akseptabilitas, melainkan konsumen sudah mengetahui akan pentingnya asuransi dalam kehidupan terutama dalam menghadapi masa depan yang penuh ketidakpastian. Dengan banyaknya manfaat yang diberikan oleh asuransi, maka konsumen memutuskan untuk membeli atau menggunakan produk asuransi. Dengan demikian keputusan konsumen untuk membeli asuransi Prudential lebih didorong oleh faktor manfaat dari asuransi tersebut bukan karena sesuai tidaknya produk dengan kebutuhan konsumen. 
Hipotesis kedua yang menyatakan bahwa kompetensi penyedia jasa asuransi berpengaruh positif terhadap keputusan pembelian asuransi, terbukti. Ditunjukkan oleh nilai koefisien regresi sebesar 0,280 dan nilai probabilitas sebesar $0,028<0,05$. Kompetensi merupakan kemampuan yang dimiliki oleh seorang individu pada bidang tertentu. Dengan demikian yang dimaksud dengan kompetensi penyedia jasa asuransi adalah kemampuan, kecakapan yang berasal dari pengetahuan, keterampilan, nilai dan sikap penyedia jasa asuransi untuk memenuhi semua kebutuhan nasabah. Selain itu, penyedia jasa juga harus mampu memberikan penjelasan kepada konsumen tentang manfaat produk-produk asuransi dari Prudential. Komptensi penyedia jasa asuransi meliputi empat aspek yaitu kepedulian, kemampuan memuaskan kebutuhan nasabah, kemampuan menyediakan layanan yang berkualitas dan mampu membantu dalam pembuatan kontrak asuransi (Ulbinaite, 2013). Semakin tinggi kompetensi yang dimiliki penyedia jasa maka konsumen akan memutuskan untuk membeli asuransi. Penelitian Ulbinaite (2013) mengidentifikasi bahwa kompetensi penyedia jasa asuransi merupakan faktor determinan pembelian asuransi di Lithuania.

Hipotesis ketiga yang menyatakan bahwa sikap moneter konsumen pada asuransi berpengaruh positif terhadap keputusan pembelian asuransi, terbukti. Ditunjukkan oleh nilai koefisien regresi sebesar 0,295 dan nilai probabilitas sebesar $0,019<0,05$. Sikap moneter konsumen terhadap asuransi merupakan persepsi konsumen terhadap asuransi sebagai suatu investasi yang menguntungkan.Dalam hal ini konsumen menganggap bahwa asuransi merupakan suatu tabungan yang pada saatnya nanti dapat diambil. Hal ini berarti konsumen menganggap asuransi bukan sebagai protektif yang mengisyaratkan biaya sehingga memberi kesan negatif, tapi sebuah tabungan yang dapat memberikan keuntungan pada suatu saat nanti.Sikap moneter konsumen terhadap asuransi meliputi tiga aspek, yaitu asuransi sebagai investasi, asuransi menjaga keamanan dan asuransi memberikan keuntungan (Ulbinaite, 2013). Semakin baik persepsi konsumen pada asuransi maka akan semakin tinggi juga keputusan konsumen dalam membeli asuransi. Penelitian Ulbinaite (2013) mengidentifikasi bahwa sikap moneter konsumen terhadap asuransi merupakan faktor determinan pembelian asuransi di Lithuania.

Hipotesis keempat yang menyatakan bahwa pengalaman positif pengguna jasa asuransi berpengaruh positif terhadap keputusan pembelian asuransi, terbukti.Ditunjukkan oleh nilai koefisien regresi sebesar 0,307 dan nilai probabilitas sebesar 0,015.Pengalaman merupakan suatu persepsi yang dirasakan oleh konsumen setelah mencoba asuransi. Pengalaman ini dapat berupa pengalaman sendiri maupun pengalaman orang lain. Dengan melihat dan mendengar pengalaman positif orang lain yang menggunakan asuransi, seorang konsumen akan tertarik dan memutuskan untuk menggunakan asuransi. Sebliknya, apabila pengalaman yang dilihatnya tersebut tidak baik, maka konsumen tidak akan tertarik untuk membeli asuransi. Pengalaman positif pengguna jasa asuransi meliputi empat aspek, yaitu keinginan berbagi pengalaman, menggunakan informasi asuransi yang berbeda, membuat keputusan karena pengalaman orang lain dan melakukan pertimbangan sebelum memutuskan (Ulbinaite, 2013). Penelitian Ulbinaite (2013) mengidentifikasi bahwa pengalaman positif pengguna jasa asuransi merupakan faktor determinan pembelian asuransi di Lithuania.

\section{SIMPULAN}

Berdasarkan hasil analisis diatas maka dapat diambil kesimpulan sebagai berikut:

a. Akseptabilitas kondisi asuransi tidak berpengaruh signifikan terhadap keputusan pembelian asuransi. Hal ini ditunjukkan dengan tingkat signifikansi $(0,644)$ yang lebih besar dari 0,05 .

b. Kompetensi penyedia jasa asuransi berpengaruh positif terhadap keputusan pembelian asuransi. Hal ini ditunjukkan dengan tingkat signifikansi $(0,028)$ yang kurang dari 0,05. Kompetensi penyedia jasa 
asuransi terlihat dari aspek kepedulian pada permasalahan, memberikan kepuasan, memberikan pelayanan, sikap yang ramah dan membantu klien.

c. Sikap moneter konsumen pada asuransi berpengaruh positif terhadap keputusan pembelian asuransi. Hal ini ditunjukkan dengan tingkat signifikansi $(0,019)$ yang kurang dari 0,05. Sikap moneter konsumen terhadap asuransi tercermin pada adanya anggapan bahwa asuransi sebagai investasi masa depan, tabungan masa depan, terlindungi, memberikan keuntungan dan memberikan manfaat.

d. Pengalaman positif pengguna jasa asuransi berpengaruh positif terhadap keputusan pembelian asuransi. Hal ini ditunjukkan dengan tingkat signifikansi $(0,015)$ yang kurang dari 0,05 . Pengalaman positif pengguna jasa asuransi tercermin pada aspek membagi pengalaman kepada orang lain, menggunakan informasi, mencari informasi, melihat pengalaman teman, pengalaman orang lain yang penting dan pengalaman teman.

\section{REFERENSI}

Endarmoko. 2006. Tesaurus Bahasa Indonesia. Jakarta: Gramedia Pustaka

Ferdinand, Augusty. 2006. Metode Penelitian Manajemen. Semarang: BP Undip

Ghozali, Imam. 2011. Aplikasi Analisis Multivariate Dengan Program SPSS for Windows. Semarang: BP UNDIP

Ghozali, I dan A. Chariri. 2007. Teori Akuntansi. Semarang: BP Undip

Haque, Ahasanul, Sabbir Rahman, Ali Khatibi. 2010. Factors Influencing Consumer Ethical Decision Making of Purchasing Pirated Software: Structural equation Modelling on Malaysian Consumer. Journal of International Business Ethics. Volume 3 Nomor 1

Iriani, Yani dan Maria Barokah. 2012. Analisis factor-Faktor yang Mempengaruhi Perilaku Konsumen dalam Pembelian LPG 3 KG. Jurnal Ekonomi. Bandung: Universitas Widyatama
Joseph F. hair, 1998. Multivariate Data Analysis. International Edition. Prentice Hall

Kirana, Putri. 2009. Analisis Factor-Faktor yang Mempengaruhi Loyalitas Konsumen pada Asuransi Prudential di Kota Semarang. Skripsi. Fakultas Ekonomi Universitas Diponegoro Semarang

Kotler, Philip dan Gary Armstrong. 2008. Prinsip-Prinsip Pemasaran. Jilid 1 Jakarta: Erlangga

Kotler, Philip. 2006. Manajemen Pemasaran. Jakarta: Erlangga

Loehoer, Robert. 2002. Manajemen Sumber Daya Manusia. Jakarta: Salemba Empat

Mowen, J.C \& Michael Minor. 2002. Perilaku Konsumen. Jilid 1. Terjemahan. Jakarta: Erlangga

Mulyasa. 2004. Kurikulum Berbasis Kompetensi, Konsep, Karakteristik dan Implementasi. Bandung: Remaja Rosdakarya

Nurnaningsih, Ratih. 2012. Pengaruh Promosi, Harga dan Kualitas Layanan terhadap Keputusan Pembelian jasa Asuransi Jiwa. Skripsi. Fakultas Ekonomi Universitas Diponegoro Semarang

Schiffman, Leon dan Kanuk, Leslie Lazar. 2004. Perilaku Konsumen. Jakarta: PT Indeks

Setiadi, Nugroho. 2003. Perilaku Konsumen. Jakarta: Kencana

Sunyoto, Danang. 2013. Dasar-Dasar Manajemen Pemasaran. Yogyakarta: Caps

Suparmo. 2001. Membangun Kompetensi Dasar. Jakarta: Dirjen Pendidikan Tinggi Departemen Pendidikan Nasional

Suryani, Tatik. 2008. Perilaku Konsumen: Implikasi pada Strategi Pemasaran. Yogyakarta: Graha Ilmu

Sutisna. 2002. Perilaku Konsumen dan Komunikasi Pemasaran. Bandung: remaja Rosdakarya

Ulbinaite, Aurelija, Marija Kucinskiene and Yannick Le Moullec. 2013. 


\section{JURNAL MANAJEMEN VOL. 6 N0. 1 JUNI 2016}

Determinants of Insurance Purchase Winardi, 1991. Pengantar tentang Riset Decision making in Lithuania. pemasaran. Bandung: Mandar Maju Inzinerie Ekoomika-Engineering www.okezone.com diakses tanggal 9 Oktober Economics. 24 (2) 2015

Uno, Hamzah. 2011. Teori Motivasi dan Pengukurannya: Analisis di Bidang pendidikan. Jakarta: Bumi Aksara

http://irfanisprayudhi.wordpress.com, diakses tanggal 9 Oktober 2015

www.prudential.com diakses tanggal 1 Oktober 2015 